\begin{tabular}{|c|c|}
\hline \multirow{3}{*}{ 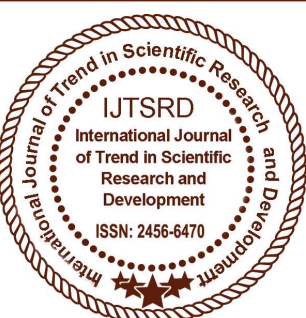 } & $\begin{array}{l}\text { International Journal of Trend in Scientific } \\
\text { Research and Development (IJTSRD) }\end{array}$ \\
\hline & Access Journal \\
\hline & ISSN No: 2456 - 6470 | www.ijtsrd.com | Volume - 2 | Issue -3 \\
\hline
\end{tabular}

\title{
A3P approach towards Improving Privacy for Uploaded Images on the Content Sharing Sites
}

\author{
T. Sasikala \\ MCA Final Year, \\ LakiReddy BaliReddy College of Engineering, \\ Mylavaram, Andhra Pradesh, India
}

\author{
I. Rajendra Kumar \\ Associate Prof \& HOD, Department of MCA, \\ LakiReddy BaliReddy College of Engineering, \\ Mylavaram, Andhra Pradesh, India
}

\section{ABSTRACT}

The developing volume of pictures clients share through social destinations, watching security has turned into a significant issue, as exhibited by a current influx of Public episodes where clients accidentally shared private data. In light of these episodes, the need of apparatuses to enable clients to control access to their common substance is obvious. Toward tending to this need, we proposed an Adaptive Privacy Policy Prediction (A3P) framework to enable client to involve security settings their pictures. We analyze the part of social setting, picture substance, and metadata as conceivable pointers of client's protection inclinations. We propose a twolevel framework which as showed by the customer's available history on the site, chooses the best open methodology for the customer's pictures being exchanged. Our answer relies upon a photo portrayal structure for picture classes which may be connected with relative methodologies, and on a methodology desire figuring to therefore make a game plan for each as of late exchanged picture, similarly as demonstrated by customer's social components. After some time, the made courses of action will take after the progression of customer's security attitude. We give the results of our wide appraisal in excess of 5,000 methodologies, which show the ampleness of our structure, with conjecture rightness' in excess of 90 percent.

Keywords: Image Classification, Adaptive Policy Prediction and Feature selection.

\section{Introduction}

Pictures are by and by one of the key engaging operators of customers' system. Sharing happens both among officially settled get-togethers of known people or gatherings of companions (e.g., Google+, Flickr or Picasa), and besides dynamically with people outside the customers gatherings of companions, for inspirations driving social disclosure to enable them to recognize new partners and get some answers concerning colleagues interests and social condition. Regardless, semantically rich pictures may reveal content sensitive information. Consider a photograph of an understudy's 2012 graduation work, for instance. It could be shared inside a Google + circle or Flickr group, however may irrationally uncover the understudies BApos relatives and differing accomplices. Sharing pictures inside online substance sharing objectives, in this way, may rapidly actuate disastrous presentation and security infringement. Propel, the proceeding on technique for online media makes it workable for different clients to aggregate rich accumulated data about the proprietor of the passed on substance and the subjects in the dispersed substance. The accumulated data can accomplish sudden presentation of one's social condition and incite destroy of one's very close data.

\section{Literature Survey}

Imagined community: Awareness, information sharing, and insurance on the Facebook. 
Online easygoing relationship, for example, Friendster, MySpace, or the Facebook have encountered exponential headway in selection beginning late. These systems offer drawing in implies for among activity and correspondence additionally raise affirmation and security concerns. In this review we contemplate an administrator trial of the general population from the Facebook (a social relationship for universities and discretionary schools) at a US instructive establishment, and adjust the examination information with data recovered from the net-work itself. We filter for significant estimation or behavioral complexities between the social affairs of the structure's kin and non-individuals; we isolate the effect of security weights on individuals coordinate; we separate individuals' conveyed affectation and real lead; and we account the alterations in lead coming to fruition to protection related data introduction.

A Survey on the Privacy Settings of User Data and Images on Content Sharing Sites: Web based frameworks organization's wound up being a champion among the most essential piece of our standard day by day presence as it empowers us to chat with various individuals. Age of long range social correspondence regions, for texample, MySpace, LinkedIn, and Facebook, people are offered chances to meet new individuals and associates in their own particular what's more in the other masterminded get-togethers over the world. Clients of social joint effort associations give a wealth of individual data to an extensive number of "partners." This redesigned improvement prompts security infringement where the clients are sharing the gigantic volumes of pictures crosswise over completed more number of social requests. This affirmation should be taken care with a specific genuine goal to update the consumer loyalty level.

Privacy Stories: Trust in Privacy Behaviors through End User Programming

This paper appear, In the pursuit to give clients indispensable control over their data, we ought to consider End User Programming methodologies as a conceivable swap for either dull, pro picked decisions or the perpetual improvement of choices that ascents up out of a senseless use of direct control measures. We portray a work early to think the sensibility of this approach for enhancing the ease of use of social affiliation protection design. We make utilization of investigative solace methodology to review the comfort inconveniences of the current Facebook interface and to train the format as for our proposed elective. We by then give a record of a little (twoclient) pilot study and take a gander at challenges that we will address in future outline highlights.

Techniques and Struggles with Privacy in an Online Social Networking Community: Online long range easygoing correspondence get-togethers, for example, Facebook and MySpace are to an unprecedented degree well known. These areas have changed what number of individuals make and keep up relationship through posting and sharing individual data. The entire and importance of these individual exposures have expedited stresses up concerning the web security. We make past research on clients' under-use of open security choices by looking at clients' repeating design structures for keeping up their affirmation, and where those techniques bomb, on the online easygoing affiliation website Facebook. Our outcomes show the need for parts that give nature with the security effect of clients' well ordered facilitated endeavors.

\section{Architecture}

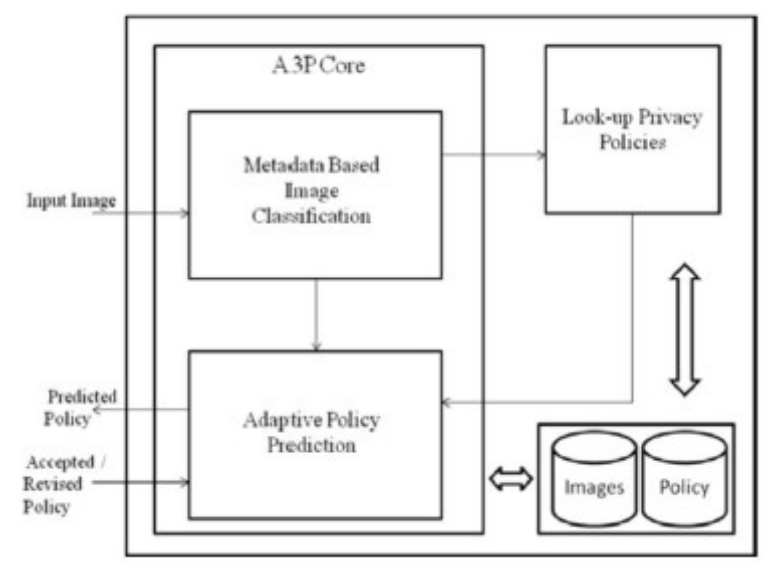

Framework Overview: The A3P framework incorporates two standard segments: A3P-center and A3P-social. The general information stream is the running with. Precisely when a client trades a photograph, the photograph will be first sent to the A3P-center. The A3P-center bunches the photograph and picks if there is a need to summon the A3P-social. Everything considered, the A3P-center predicts approaches for the clients especially in context of their true blue lead. In the event that one of the running with two cases is avowed honest to goodness, A3P-center will summon A3Psocial: (i) The client does not have enough information for the sort of the traded picture to lead blueprint want; (ii) The A3Pcenter sees the present bona fide changes among the 
client's social occasion about their security hones close by users. Enlargement of long range easygoing correspondence works out (augmentation of new mates, new posts on one's profile and so forth). In above cases, it is gainful to answer to the client the most recent security routine of social gatherings that have similar establishment as the customer. The A3Pparties clients into get-togethers with equivalent social setting and security incline, and dependably screen the social affairs. Right when the A3P-social is summoned, it in this manner perceives the party for the client and sends back the data about the social affair to the A3P-put for blueprint want. Around the end, the normal approach will be appeared to the client. In the event that the client is completely fulfilled by the normal strategy, he or she can simply remember it. Something special, the client can change the strategy. The approach system will be secured in the plan vault of the structure for the course of action gauge of future exchanges.

A3P-Core: There are two fundamental parts in A3Pcenter: (I) Image strategy and (ii) Adaptive framework want. For every client, his/her photographs are at first sorted out in context of substance and metadata. By at that point, affirmation blueprints of every portrayal of pictures are inspected for the approach figure. Tolerating a two-form approach is more sensible for procedure proposition than applying the general one-arrange information mining ways to deal with deal with mine both picture parts and systems together. Survey that when a customer exchanges another photo, the customer is sitting tight for a recommended methodology. The two-sort out approach empowers the system to use the essential stage to portray the new picture and find the contender sets of pictures for the subsequent course of action proposition. As for the one-organize mining approach, it would not have the ability to Locate the right class of the new picture since its portrayal criteria require both picture features and methodologies while the courses of action of the new picture are not open yet.

\section{Image Classification}

Content-Based Classification: Our approach to manage regulates substance develop request is arranged in light of a gainful however then right picture likeness approach. Specifically, our delineation incorporate considers picture marks depicted perspective of evaluated and cleaned sort of Haar wavelet change. For each photo, the wavelet change encodes repeat and spatial information related to picture shading, evaluate, invariant change, shape, surface, symmetry, and so forth. By then, couple of coefficients is formed the sign of the photo. The substance closeness among pictures is then planned by the division among their photo marks.

Adaptive Policy Prediction: The approach want tally gives a normal course of action of a starting late traded picture to the client for his/her reference. All the more essentially, the normal technique will mirror the conceivable changes of a client's security concerns. The guess technique includes three focal stages: (I) approach standardization; (ii) framework mining; and (iii) game-plan want. The procedure organization is a principal crumbling technique to change over a client approach into an arrangement of nuclear norms in which the information (D) partition is a solitary section set.

\section{Algorithms}

Bayesian Information Criterion Template matching algorithm: Picture arranging is a most fundamental theme in the field of picture managing, and it is most all things considered utilized as a bit of a photograph enlistment and picture mix. This tally in light of a projection and consecutive closeness seeing is proposed. Figuring procedure is from drawing in sorting out to detail arranging. Instantly, unfaltering pictures are relied upon to get one estimation information and its authorities for portray arranging with one estimation information with reference picture. Moreover, consecutive comparability seeing standard is utilized for detail arranging utilizing the fixations with more prominent similarity in plot sorting out. This estimation was fit and speedier than other picture arrange arranging check.

\section{Conclusion}

The Adaptive Privacy Policy Prediction (A3P) framework that empowers clients to mechanize the affirmation philosophy settings for their traded pictures. The A3P framework gives a broad structure to reason security inclines in context of the data open for a given client. The issue of cool begins;utilizing social setting data was in like way acceptably dealt with. Our trial considers displays that $\mathrm{A} 3 \mathrm{P}$ is a sensible device that offers imperative overhauls over current ways to deal with oversee security. 
The A3Pcore centers around dissecting every individual client have pictures and metadata, while the A3P Social offers a get-together viewpoint of protection setting proposals for client potential security change. The joint exertion streams between the two building pieces to change the positive conditions from meeting solitary attributes and securing bunch exhortation.

\section{References}

1) L. Church, J. Anderson, J. Bonneau, and F. Stajano, "Privacy stories: Confidence on privacy behaviors through end user programming," in Proc. 5th Symp. Usable Privacy Security, 2009.

2) R. da Silva Torres and A. Falc ao, "Contentbased image retrieval: Theory applications," Revista de Informatica_Teorica_e Aplicada, vol. 2, no. 13, pp. 161-185, 2006.

3) R. Datta, D. Joshi, J. Li, and J. Wang, "Image retrieval: Ideas, influences, and trends of the new age," ACM Comput. Surv., vol. 40, no. 2, p. 5, 2008.

4) J. Deng, A. C. Berg, K. Li, and L. FeiFei, "What does classifying more than 10,000 image categories tell us?" in Proc. 11th Eur. Conf. Comput. Vis.: Part V, 2010, pp. 71-84.

5) A. Kapadia, F. AduOppong, C. K. Gardiner, and P. P. Tsang, "Social circles: Tackling privacy in social networks," in Proc. Symp. Usable Privacy Security, 2008.

6) L. Geng, H. J. Hamilton, "Interestingness measures for data mining: A survey," ACM Comput. Surv., vol. 38, no. 3, p. 9, 2006.

7) Image-net data set. [Online]. Available: www.image-net.org, Dec. 2013.

8) S. Jones, E. O'Neill, "Contextual dynamics of group-based sharing decisions," in Proc. Conf. Human Factors Comput. Syst., 2011, pp. 17771786.
9) A. Kaw, E. Kalu, Numerical Methods with Applications: Abridged., Raleigh, North Carolina, USA: Lulu.com, 2010.

10) A. Acquisti, R. Gross, "Imagined communities: Awareness, information sharing, and privacy on the facebook," in Proc. 6th Int. Conf. Privacy Enhancing Technol. Workshop, 2006,pp. 36-58.

11) R. Agrawal, R. Srikant, "Fast algorithms for mining association rules large databases," in Proc. 20th Int. Conf. Very Large Data Bases, 1994, pp. 487-499.

12) S. Ahern, D. Eckles, N. S. Good, S. King, M. Naaman, R. Nair,"Over-exposed?: Privacy patterns considerations in online and mobile photo sharing," in Proc. Conf. Human Factors Comput. Syst., 2007, pp. 357-366.

13) M. Ames, M. Naaman, "Why we tag: Motivations for annota-tion in mobile and online media," in Proc. Conf. Human Factors Comput. Syst., 2007, pp. 971-980.

14) A. Besmer, H. Lipford, "Tagged photos: Concerns, percep-tions, and protections," in Proc. 27th Int. Conf. Extended Abstracts Human Factors Comput. Syst., 2009, pp. 4585-4590.

15) D. G. Altman, J. M. Bland,"Multiple significance tests: The bonferroni method," Brit. Med. J., vol. 310, no. 6973, 1995.

16) J. Bonneau, J. Anderson, L. Church, "Privacy suites: Shared privacy for social networks," in Proc. Symp. Usable Privacy Security, 2009.

17) J. Bonneau, J. Anderson, G. Danezis, "Prying data out of a social network," in Proc. Int. Conf. Adv. Soc. Netw. Anal. Mining., 2009, pp.249-254.

18) H.-M. Chen, M.-H. Chang, P Chang, M.-C. Tien, W. H. Hsu, and J.-L. Wu, "Sheepdog: Group and tag recommendation flickr photos by automatic search-based learning," in Proc. 16th ACM Int. Conf. Multimedia, 2008, pp. 737-740. 